\title{
New Cardiovascular Risk Factors and Physical Activity
}

\author{
Nicolás Terrados ${ }^{1,2}$ and Eduardo Iglesias-Gutiérrez ${ }^{2}$ \\ ${ }^{1}$ Regional Sports Medicine Unit of the Principality of Asturias, Avilés, \\ ${ }^{2}$ Department of Functional Biology, \\ The University of Oviedo, Asturias, \\ Spain
}

\section{Introduction}

A cardiovascular risk factor (CRF) is a biological characteristic or behaviour that increases the possibility of cardiovascular disease (CVD) (1). The concept of risk factors first appeared some fifty years ago with the publication of the Framingham Study (2). Since that time, advances in the field of epidemiology have made large scale clinical studies possible and have led to the identification of a series of cardiovascular disease risk factors that induce the formation of atheromatous plaques. The establishment of a specific biological characteristic, environmental factor or habit as a CRF requires: a standardised methodology; concordant prospective studies; an added effect when various risk factors concur in an individual; and, that the modification of the factor (in the case that the factor is modifiable) results in a diminution of the risk (3).

Historically, there has been clear evidence of a series of 'traditional' CRFs (Table 1), such as hypercholesterolemia, hypertension, hyperglycaemia, nicotine poisoning, sedentarism, etc. which have been used in the stratification of individual risk (4). In the recent past, a number of important studies have proposed the inclusion of new or 'emergent' CRFs in the evaluation and stratification of cardiovascular risk and this has implications for preventive and therapeutic strategies.

Numerous documents and reports that include recommendations for the prevention of CVD and control of the main cardiovascular risk factors have been published by national and international scientific institutions and organisations (from the USA, Europe (5) etc.). Following the latest recommendations of the world renowned National Cholesterol Education Program (NCEP) (4), Table 1 lists the most significant 'traditional' CRFs whilst Table 2 shows the 'emergent' factors. Some of the 'new' factors have been recognised for decades though they have been subject to debate and controversy, and consensus has not been reached on their inclusion in cardiovascular risk evaluation.

The NCEP Panel III identifies three classes of CRFs that influence the possibilities of suffering CVD, although only the first two are relevant to the modification of treatment objectives: major CRFs, factors linked to lifestyles and emergent risk factors. 
Age and sex (men $\geq 45$ years old, women $\geq 55$ years old)

Nicotine poisoning

Arterial hypertension (BP $\geq 140 / 90 \mathrm{mmHg}$ or undergoing antihypertensive treatment)

Increase LDL cholesterol

Fall in HDL cholesterol $(<40 \mathrm{mg} / \mathrm{dl})^{*}$

Family history of premature coronary heart disease

Male first degree relatives $<55$ years

Female first degree relatives $<65$ years

Diabetes mellitus**

Lifestyle (overweight/obesity, sedentarism, atherogenic diet)***

* Adapted from Panel III of the National Cholesterol Education Program (4).

"If HDL cholesterol is $\geq 60 \mathrm{mg} / \mathrm{dl}$, it is considered as a 'negative' risk factor".

**Diabetes mellitus carries a risk equivalent to a secondary prevention situation.

***These factors are not computed in the algorithms for stratification of risk.

AP: arterial pressure; LDL: low density lipoproteins; HDL: high density lipoproteins.

Table 1. Major ('traditional') cardiovascular risk factors, (4).

Panel III recognises that, in addition to the main CRFs, CVD is influenced by the presence of other factors which modification can have a positive effect on some of the major CRFs and reduce risk; these therefore represent direct treatment objectives. These factors act through other intermediate elements or worsen independent risk factors such as, obesity, sedentarism, a family history of premature CVD, psychosocial conditions or being male. Although they do not figure in algorithm calculations on the stratification of risk (6), two of them, obesity and sedentarism, are considered as causal CRFs by the American Heart Association.

\section{Traditional cardiovascular risk factors}

\subsection{Lipid risk factors}

Hypercholesterolemia is one of the main cardiovascular risk factors that are modifiable. The Multiple Risk Factor Intervention Trial demonstrated the existence of a continuous and graded relationship between cholesterolemia and total mortality and mortality due to ischemic heart disease (7).

The three main classes of lipoproteins are: Low-density lipoproteins (LDL); High-density lipoproteins (HDL); and Very low-density lipoproteins (VLDL). There is another class of lipoproteins known as Intermediate-density lipoproteins (IDL) that is between VLDL and LDL, though in clinical practice, it is included in the LDL category.

With the exception of HDLs, that play a role in reverse cholesterol transport and therefore exercise a vasoprotector action, lipid particles are more atherogenic the more cholesterol that they transport. Chylomicrons carry such a small quantity of cholesterol that their increase in hyperchylomicronemia (Type I dyslipidemia) is not associated with 
atherosclerosis lesions. In contrast, with the accumulation of VLDLs, a fifth of which are made up of cholesterol, an increase in atherogenesis is observed. Given that LDLs are particles with a higher level of cholesterol, they are the main cause of atherogenesis when they are in excess.

Although LDLs receive most attention in clinical management, there is a growing body of evidence that indicates that VLDLs play an important role in atherogenesis.

Levels of HDL cholesterol are inversely related with the risk of CVD; they seem to play a protective role against the onset of atherosclerosis as they capture free cholesterol from the peripheric tissues such as the cells of the vascular wall. This cholesterol is transformed into cholesterol esters, a part of which is transferred to the VLDLs by the cholesterol esters transfer proteins (CETP) and returned to the liver by IDLs and LDLs and another part is transferred directly to the liver by the HDL particles. The liver reuses the cholesterol for the synthesis of VLDLs, for the synthesis of bile salts or excretes it directly into the bile. Therefore, HDLs tend to reduce cholesterol levels.

\subsection{Non-lipid risk factors}

\section{Hypertension}

Hypertension is a principal and independent CRF, but its damaging effect is increased when associated with other coronary risk factors such as smoking, diabetes and dyslipidemia. The Sixth Report of the Joint National Committee on Prevention, Detection, Evaluation, and Treatment of High Blood Pressure defines hypertension as a systolic arterial pressure of $\geq 140 \mathrm{mmHg}$ or diastolic $\geq 90 \mathrm{mmHg}$ or the need for antihypertensive treatment (8). A number of studies, for example the Framingham study, have demonstrated an increase in total mortality and cardiovascular risk in cases of increased levels of arterial pressure (diastolic and systolic), with a continuous and gradual relationship $(9,10,11)$. The association applies to men and women, young and old alike.

\section{Smoking}

Smoking contributes clearly to CVD. The relationship between smoking and the risk of CVD is dose dependent and affects men and women equally. Observational studies suggest that stopping smoking leads to a substantial reduction of the risk of a cardiovascular event.

\section{Diabetes}

Diabetes is defined as the presence of a level of glucose, on an empty stomach, more than, or equal to, $126 \mathrm{mg} / \mathrm{dL}$ (12). The risk of cardiovascular disease is significantly increased for sufferers of diabetes mellitus type 1 and type 2 (13). The increase of risk attributed to hyperglycaemia is independent of other risk factors such as obesity, overweight or dyslipidemia that are often observed in diabetics.

$80 \%$ of diabetes mellitus patient mortality is caused by complications associated with atherosclerosis with ischemic heart disease being responsible in $75 \%$ of cases (14). In addition, the risk of acute myocardial infarction in diabetes mellitus type 2 patients with no previous history of myocardial infarction is similar to non-diabetics who have previously suffered a heart attack (15). 
Although it is probable that strict control of diabetes reduces micro-vascular disorders and other complications such as renal disease and retinopathies, statistics relative to the effects of glycemic control on coronary episodes are uncertain. Diabetics often present dyslipidemia, characterised by moderate hypercholesterolemia and hypertriglyceridemia with low concentrations of HDL cholesterol that involve increased cardiovascular risk. This is frequently associated with central obesity, hyperinsulinism and AHT. Therefore, the association of numerous CRFs explains why many individuals already exhibit disorders when they are diagnosed with diabetes mellitus.

\section{Emergent cardiovascular risk factors}

Traditional factors can strongly predict the risk of cardiovascular disease but not completely (16). Thus, recently new biomarkers have emerged, although their predictive value still needs to be validated in multiple cohorts and different populations.

\section{Lipid Risk Factors}

Total cholesterol quotient/HDL cholesterol

Apolipoproteins

HDL subclasses

Triglycerides

“Small and dense" LDL particles

Residual or remnant lipoproteins

\section{Non-lipid Risk Factors}

Markers of inflammation

Homocysteinaemia

Impaired fasting glycaemia

Thrombogenic / hemostatic factors

LDL: Low-density lipoproteins; HDL: High-density lipoproteins

Table 2. Emergent cardiovascular risk factors

\subsection{Apolipoproteins}

\section{Apolipoprotein A}

A apolipoproteins are a group of proteins that are variably distributed among different lipoproteins. Apo A-I is the most abundant apolipoprotein in plasma and is nearly $90 \%$ of the HDL and $60-70 \%$ of the protein fraction of the sub-fractions HDL2 and HDL3, respectively. Apo A-I is initially synthesised in the liver and intestine as a protein precursor which is degraded to its mature form in plasma; it is a simple polypeptide chain that contains 243 amino acids. This protein participates in the reverse transport of cholesterol. 
The apolipoprotein apo A-II is the second highest concentration protein component of HDL, although it is absent in the HDL2 sub-fraction and plasma levels do not correlate with HDLcholesterol levels.

The measurement of the concentration of apo A-I in serum perfectly reproduces the predictive value of coronary disease of the concentration of HDL in serum. Nevertheless, this correlation is not valid in subjects with hypertriglyceridemia, in which the fraction of HDL is enriched with triglycerides and cholesterol is almost absent.

\section{Apolipoprotein B}

$\mathrm{B}$ apolipoprotein is a protein of great molecular weight, present in chylomicrons, VLDL, and LDL lipoproteins. There are two molecular forms in plasma, apo B-100 (apo B) and apo B-48. Apo B is a unique polypeptide chain of 4536 amino acids (one of the biggest plasma proteins), synthesised in the liver and secreted in VLDLs. It is quantitatively maintained during the conversion of VLDL to IDL until LDL, of which it is the only protein component, and for this reason, levels of apo B are correlated with levels of these lipoproteins. Studies have established the relationship between B concentrations in serum and cardiovascular risk $(17,18,19)$.

Given that each particle of VLDL, IDL and LDL only contains one apo B molecule, its concentration in serum reflects the risk associated with all these atherogenic particles. Although considered as a risk factor by the NCEP, its determination is not recommended in clinical practice, due to the unavailability of clinical guides or risk stratification algorithms based on its concentration, although it can be useful in some situations.

Nevertheless, from an experimental point of view, it can offer important additional information. The concentration of apo B in serum provides data on the number of particles, especially LDL particles, as they contain approximately $90 \%$ of total circulating apo B. It has been suggested that a LDL/ decreased apo B relationship is an indicator of the predominance of small and dense LDL particles (20).

The estimation of LDL cholesterol using the Friedewald formula is inexact when levels of triglycerides are higher than $300 \mathrm{mg} / \mathrm{dL}$ and, if no validated direct method or ultracentrifugation is available, the concentration of apo B can be used as an alternative for the stratification of risk and the setting of therapeutic objectives (21). A modification of the Friedewald formula has been described for the calculation of LDL cholesterol that includes apo B. The LDL cholesterol obtained in this way has been shown to be more independent of hypertriglyceridemia than calculations made with the Friedewald formula (22).

The results of some studies have shown that the relationship between apo B/apo A-I is better for evaluating cardiovascular risk than the total cholesterol/HDL cholesterol relationship or LDL cholesterol/HDL $(23,24)$. The number of particles and, in particular, the balance between them, that is to say, the apo B/apo A-I relationship, may be more important than the lipid quantity carried by each particle.

\subsection{Triglycerides}

In spite of the evidence put forward by some epidemiological studies on the relationship between hypertriglyceridemia and the incidence of CVD $(25,26)$, the results of other, more recent, multivariate works do not allow the definitive classification of triglycerides as an 
independent CRF (4). This is due to the close relationship between increased levels of triglycerides and other lipid CRFs (the presence of residual lipoproteins or remnants of VLDLs and chylomicrons in plasma, the predominance of 'small and dense' particles of LDL in plasma or decreased plasma concentration of HDL cholesterol), non-lipid CRFs (hypertension) and emergent CRFs (glucose intolerance, prothrombotic state). The NCEP Panel III states that increases in levels of triglycerides $(>200 \mathrm{mg} / \mathrm{dL})$ are associated with a higher risk of CVD. It is also commonly associated with other lipid and non-lipid risk factors and indicates that therapeutic objectives should be based on lifestyle changes (loss of weight, physical exercise, stopping smoking).

\subsection{Lipoprotein(a)}

In recent years, lipoprotein (a) (Lp(a)) has attracted enormous interest as a cardiovascular risk factor $(27,28)$. $\mathrm{Lp}(\mathrm{a})$ is a spherical lipoprotein, rich in cholesterol esters and phospholipids, it has a composition that is similar to LDL and contains a specific glycoprotein, apolipoprotein (a), linked by a disulphide bridge to the apolipoprotein B-100. In addition, it has great structural homology to the plasminogen fibrinolytic proenzyme (Figure 1) (29).

A variety of mechanisms that may explain the relationship between $\operatorname{lp}(\mathrm{a})$ and cardiovascular disease have been described in published works. Firstly, it is argued that as $1 p(a)$ is an LDL particle it plays a role in the initiation, progression and possible rupture of the atheromatous plaque. Secondly, it is suggested that this particle competes with the plasminogen particle and inhibits thrombolytic activity (30). Finally, cell line studies with rats have shown that lipoprotein (a) inhibits NO synthesis (31).

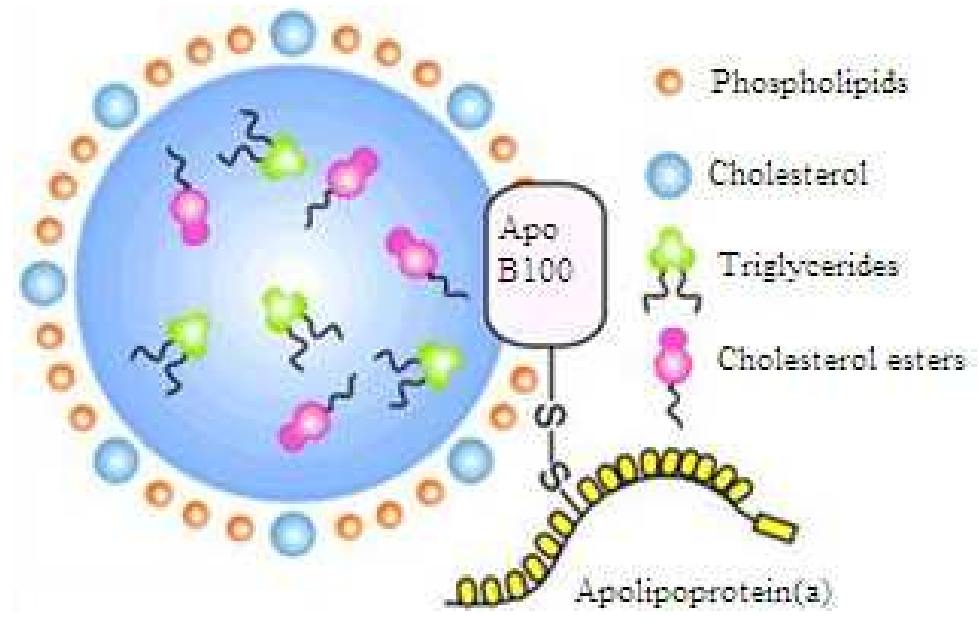

Fig. 1. Structure of lipoprotein (a).

Although an increase in the plasma concentration of $1 \mathrm{p}(\mathrm{a})$ implies a higher risk of CVD, mainly in individuals at greater global risk (32), the principal consensus documents, such as the NCEP Panel III and the latest European STORE project proposal, do not include it among cardiovascular risk factors that are computable for the evaluation of overall risk. This 
is due to the fact that some studies do not corroborate independent prediction, based on lp(a) levels, of suffering CVD $(33,34)$ and there is no evidence that elimination benefits the patient (35).

\subsection{Ultra-sensitive CRP}

The inflammatory process characterises all phases of atherothrombotic development. There are many studies that relate a variety of elements that intervene in the inflammatory process with the risk of CVD. These elements include: the intercellular-1 adhesion molecule (ICAM1); the vascular-1 adhesion molecule (VCAM-1); E-selectin; P-selectin; proinflammatory cytokines, such as interleucine-6 (IL-6), and the tumor necrosis factor-alpha (TNF- $\alpha$ ). All of the aforementioned have been shown to be predictors of CRFs (36). In clinical practice, difficulties in determining these markers and the short half-life of these molecules in circulatory blood mean that it is not possible to include them in the daily clinical routine. Of the other markers of inflammation that have been suggested, such as, serum amyloid A, the leukocyte count, fibrinogen, nitrotyrosine, myeloperoxidase and c-reactive protein (CRP), only the latter has been consolidated as a candidate due to its stability, analysis precision and accessibility (37). The AHA (American Heart Association) and CDC (Centers for Disease Control) say that of all the markers of inflammation, only ultra-sensitive CRP (US-CRP) has the characteristics necessary for use in clinical practice (38).

Ultra-sensitive CRP (US-CRP) is currently the best characterised inflammation biomarker and has been established as a potential marker of cardiovascular risk. US-CRP in plasma is a firm candidate for use in clinical practice as it is considered as an independent predictor of coronary illness for the general population, for both sexes and for patients that have already presented clinical manifestations of CVD $(36,37)$. However, sufficient evidence that reducing CRP levels prevents CHD events is lacking $(16,39)$.

CRP is a member of the pentraxin family of proteins which are characterised by having a pentameric structure and radial symmetry, formed by five protomers of $24 \mathrm{kD}$ and 206 amino acids that are linked among themselves by non covalent bonds and have the capacity to bond to a great variety of substances, such as, phosphocholine, fibronectin, chromatin, histones and ribonucleoproteins (40).

The differentiation of monocytes and macrophages, that takes place during atherosclerotic process, frees proinflammatory molecules that include interleukin-6 (IL-6) which activates, in the liver, the liberation of inflammation markers like CRP. High levels (>10 mg/dl) are registered in bacterial infections though ultra-sensitive analysis can detect very low levels $(0-3 \mathrm{mg} / \mathrm{dl})$ that are associated with the atherosclerotic process. Their half-life is more than 24 hours and their blood levels are not altered by diet.

\subsection{Homocysteine}

In the last decade, numerous studies have been published that relate increases homocysteinaemia (Hcy) to CVD (41-45). Nevertheless, the mechanism that controls this relationship is not completely understood. Homocysteine has a direct cytotoxic effect on endothelial cells in cultivation. An alteration in endothelial function has been observed, evaluated by echo-Doppler, in individuals with moderate hyperhomocysteinaemia and 
improvements have been noted on reducing the concentration of homocysteine by means of folic acid treatment. It should be remembered that levels of plasma homocysteine are related to levels of vitamin $\mathrm{B}_{12}$ and folic acid (46).

Homocysteine can promote LDL oxidation through the production of reactive oxygen species such as hydrogen peroxide and studies have described the promotion of the multiplication of smooth muscle cells and a reduction in DNA synthesis in endothelial cells. A large number of prospective and retrospective studies support the hypothesis that an excess of plasma homocysteine is associated with a higher risk of coronary illness, peripheral and cerebrovascular disease (44,47-49).

\subsection{Asymmetric dimethylarginine}

The relationship established between a high concentration of asymmetric dimethylarginine (ADMA) and endothelial dysfunction and the possible relationship between high ADMA values and the incidence of cardiovascular accidents, has led a number of research groups to study the association between high ADMA and death by any cause.

Some studies indicate that ADMA plasma levels may predict the risk of cardiovascular events. In 2001, Valkonen et al. (50) showed that subjects with ADMA levels of more than $0.62 \mu \mathrm{mol} / \mathrm{L}$ (percentile 75) had almost four times more risk of suffering an acute cardiovascular event. Similar results have been described by other authors in cases of patients with unstable angina; it was noted that those patients with higher ADMA levels $(>0,62 \mu \mathrm{mol} / \mathrm{L}$, percentile 75$)$ had five times more risk of suffering a cardiovascular event (51).

Zoccali et al. (52) showed that in haemodialysis patients, ADMA plasma levels are an independent predictor of mortality and cardiovascular risk. In their multivariate study, only ADMA and age were significantly predictive, independent of the incidence of cardiovascular episodes (such as chest angina and heart attack) and death by any cause. Patients whose concentration of plasma ADMA was above the percentile 75, had three times more risk of suffering a cardiovascular episode than patients whose initial ADMA levels were lower than the average.

There are currently a number of case studies, controls and prospective clinical trials taking place with a variety of patient populations that are aimed at gaining greater understanding of the role of ADMA as an independent risk factor for CVD and mortality. The data generated by these studies will help in determining the significance of ADMA as a risk factor and explore its diagnostic importance in different illnesses and diseases.

\section{Cardiovascular risk factors and physical activity}

There is much research on the effect of physical activity on the alteration of risk factors associated with heart disease. The most beneficial effect of exercise is on the level of oxidative metabolism which influences levels of lipids in the blood. Aerobic exercise reduces levels of triglycerides and total cholesterol and may increase levels of HDLs, especially if accompanied by weight loss. Although reductions in total cholesterol and LDL cholesterol generated by physical exercise seem to be relatively small (in general, they are less than $10 \%)$, there are important increases in HDL cholesterol and significant reductions in 
triglycerides. Transversal studies with trained athletes and non-trained subjects unequivocally demonstrate that individuals with higher levels of aerobic activity have higher HDL levels and lower levels of triglycerides (53), even after a single session of exercise (54). Nevertheless, results from longitudinal studies, over relatively long periods of time, are much less clear. Many studies on physical exercise have described an increase in HDL and a reduction in triglycerides $(53,55)$, but others have described very small changes or no changes at all. However, almost all studies have shown that proportions of LDL/HDL and total cholesterol/HDL fall after endurance training and this means less cardiovascular risk

There are reliable data that demonstrate the effectiveness of physical exercise on the reduction in blood pressure in patients with mild or moderate hypertension. Endurance training can reduce systolic and diastolic arterial pressure (DAP) by approximately 10 $\mathrm{mmHg}$ in individuals with moderate essential hypertension.

With regards to the other traditional cardiovascular risk factors, physical exercise can play a role in the reduction and control of weight and in the control of diabetes. Exercise has also been shown to be effective in the control and reduction of stress and anxiety (56).

Whilst the effect of exercise on 'traditional' CRFs is well documented, the effect of exercise on 'emergent' CRFs has not been studied in depth and results are not well known. It must not be forgotten that is very important the change in the volume of blood that affects plasma concentrations, independently of changes in total lipids, both in terms of lipids and the other biochemical parameters expressed as a concentration, for the evaluation of changes engendered by physical exercise. The failure to correctly take this factor into account could explain some of the controversies concerning studies on CRFs and physical exercise.

The beneficial effects of exercise, leading to the reduction of levels of apolipoprotein $B$, have been widely reported, but this has not been the case with the relationship between exercise and levels of apolipoprotein A-I $(57,58)$. Some authors have found that long-term, regular physical exercise does not seem to modify levels of apolipoproteins in comparison with sedentary groups (59). There is relatively little information available on levels of lipoprotein (a) in young people although some studies have confirmed a favourable relationship between regular physical exercise and levels of lipoprotein (a) $(57,59)$, whilst others found no difference in lipoprotein (a) concentration between healthy sedentary individuals and professional endurance athletes (60).

The previously mentioned studies have been undertaken by different authors with different population groups and there are no published works that, at the same time, analyse the influence of intense physical exercise and the influence of continuous physical exercise (training) on levels of apolipoproteins A-I, B and lipoproteins (a), in the same population group.

The beneficial effects of physical exercise also seem to be related to the effect on the inflammatory process. In the short term, intense physical exercise produces a transitory inflammatory response which is reflected in an increase in acute phase reactants and cytokines that is proportional to the amount of exercise and muscle damage. Nevertheless, regular physical activity (training) is associated with a chronic anti-inflammatory response that influences levels of acute phase reactants such as ultra-sensitive CRP and also affects 
lipids and lipoproteins (61-64). However, Sadepghipour et al. in 2010 found no relationship between CRP and physical activity in schoolchildren (65).

Some factors (BMI, the sex of the subject, the moment when the post-exercise sample is taken, diet, etc.), can have an influence on the values measured of ultra-sensitive CRP in response to physical exercise (62). Another issue that must be taken into account is that many studies that have examined the effects of intense physical exercise on levels of ultrasensitive CRP have not made a concentration correction in accordance with the changes in plasma volume after exercise (62). Results should be individually corrected according to the post-exercise levels of hemoconcentration or hemodilution (66).

\section{Effect of exercise on Traditional and Emergent cardiovascular risk factors}
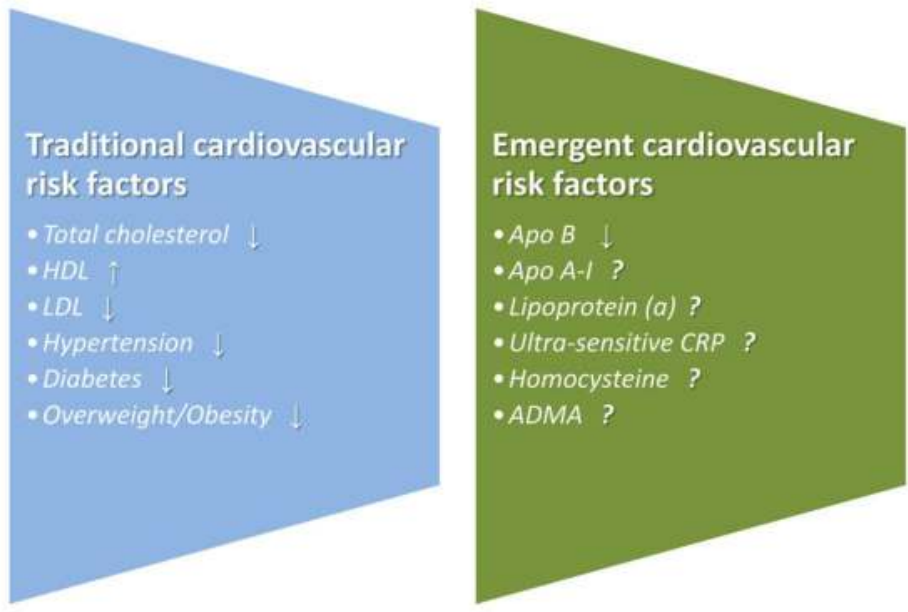

With regards to homocysteine, studies with large population groups have shown that regular physical exercise can reduce homocysteine plasma levels $(47,67,68)$. However, other studies have concluded that intense physical exercise increases levels of Hcy $(69,70)$. More recent studies, undertaken by our work group (71), demonstrate increased plasma homocysteine levels, both in total and reduced, after intense exercise. This increase is independent of the type of exercise and the vitamin levels but could be related to changes in renal function (71). The mechanism of this effect is not clearly understood though a study on alterations in the redox state of the homocysteine might lead to the comprehension of the underlying process. Furthermore, a study on its relationship with plasma concentrations of NO, ADMA and their proximate metabolites might lead to an understanding of how intense physical exercise produces an increase in levels of homocysteine, as long as regular, moderate physical exercise (training) seems to be a beneficial modulator of homocysteine. Also related to homocysteine, is the proven fact that regular physical exercise produces a series of beneficial effects on oxidative metabolism which result in less oxidative stress and a greater defensive capacity against oxidative damage; this is caused by the increase in activity of endogenous antioxidant systems and the greater resistance of the LDL particles to 
oxidation $(71,72)$. All this signifies a reduction in oxidised LDL levels and systematic markers of inflammation, as explained by Arquer et al., in 2010 (72).

In spite of the fact that the role of ADMA as a cardiovascular risk marker is reflected in an increasing number of clinical studies and scientific publications, very few studies have looked at the effect of intense or sustained (training) physical exercise on ADMA plasma levels, with contradictory results. While Schlager et al., in 2011, found that supervised exercise training, twice a week during six months, in peripheral arterial disease patients decreases ADMA (73), Seljeflot et al., in 2011, observed no effect of 4 weeks of exercise training in ADMA concentration in patients with chronic heart failure, speculating that the duration of the exercise protocol could be insufficient to find any effects of exercise into significant changes in ADMA (74).

It is therefore recommended that studies should be undertaken on the effect of intense and sustained (training) physical exercise on emergent cardiovascular risk factors, especially on homocysteine and ADMA.

\section{Conflict of interests}

The authors have no conflicts of interest

\section{Acknowledgements}

This work has been made possible by the support of the Ministry of Science and Innovation, Carlos III Institute of Health, F.I.S. (PI020665)

\section{References}

[1] Kannel W, Dawber TR, Kagan A, Revotskie N, and Stokes J III. Factors of risk in the development of coronary heart disease-six year follow-up experience. Ann Intern Med. 1961; 55:33-50.

[2] Dawber TR, Meadors GF, Moore FE Jr. Epidemiological approaches to heart disease: the Framingham Study. Am J Public Health Nations Health. 1951; 41(3):279-81.

[3] Wilson PW, D’Agostino RB, Levy D, Belanger AM, Silbershatz H, Kannel WB. Prediction of coronary heart disease using risk factors categories. Circulation. 1998; 97(18):1837-47.

[4] Expert Panel on Detection, Evaluation, and Treatment of High Blood Cholesterol in Adults. Executive Summary of the Third Report of the National Cholesterol Education Program (NCEP) Expert Panel on Detection, Evaluation, and Treatment of High Blood Cholesterol in Adults (Adult Treatment Panel III). JAMA. 2001; 285(19):2486-97.

[5] De Backer G, Ambrosioni E, Borch-Johnsen K, Brotons C, Cifkova R, Dallongeville J, Ebrahim S, Faergeman O, Graham I, Mancia G, Manger Cats V, Orth-Gomér K, Perk J, Pyörälä K, Rodicio JL, Sans S, Sansoy V, Sechtem U, Silber S, Thomsen T, Wood D; Third Joint Task Force of European and Other Societies on Cardiovascular Disease Prevention in Clinical Practice. European guidelines on cardiovascular disease prevention in clinical practice. Third Joint Task Force of European and 
Other Societies on Cardiovascular Disease Prevention in Clinical Practice. Eur Heart J. 2003; 24(17):1601-10.

[6] Grundy SM. Primary prevention of coronary heart disease: integrating risk assessment with intervention. Circulation. 1999; 100(9):988-98.

[7] Stamler J, Wentworth DN, Neaton JD. Is relationship between serum cholesterol and risk of premature death from coronary heart disease continuous and graded? Findings in 356.222 primary screenees of the Multiple Risk Factor Intervention Trial (MRFIT) JAMA. 1986; 256(20):2823-8.

[8] The sixth report of the Joint National Committee on Prevention, Detection, Evaluation, and Treatment of High Blood Pressure. Arch Intern Med. 1997; 157(21):2413-46.

[9] MacMahon S, Peto R, Cutler J, Collins R, Sorlie P, Neaton J, Abbott R, Godwin J, Dyer A, Stamler J. Blood pressure, stroke, and coronary heart disease. Part 1, prolonged differences in blood pressure: prospective observational studies corrected for the regression dilution bias. Lancet. 1990; 335(8692):765-74.

[10] Staessen JA, Fagard R, Thijs L, Celis H, Arabidze GG, Birkenhäger WH, Bulpitt CJ, de Leeuw PW, Dollery CT, Fletcher AE, Forette F, Leonetti G, Nachev C, O'Brien ET, Rosenfeld J, Rodicio JL, Tuomilehto J, Zanchetti A. Randomised double-blind comparison of placebo and active treatment for older patients with isolated systolic hypertension. The Systolic Hypertension in Europe (Syst-Eur) Trial Investigators. Lancet 1997; 350(9080):757-64.

[11] Franklin SS, Khan SA, Wong ND, Larson MG, Levy D. Is pulse pressure useful in predicting risk for coronary heart disease? The Framingham Heart Study. Circulation. 1999; 100(4):354-60.

[12] Expert Committee on the Diagnosis and Classification of Diabetes Mellitus. Report of the expert committee on the diagnosis and classification of diabetes mellitus. Diabetes Care. 2003;26(Suppl 1):S5-20.

[13] Kannel WB, McGee DL. Diabetes and cardiovascular disease: the Framingham Study. JAMA. 1979; 241(19):2035-8.

[14] Laakso M, Lehto S. Epidemiology of risk factors for cardiovascular disease in diabetes and impaired glucose tolerance. Atherosclerosis. 1998; 137(Suppl 1):S65-73.

[15] Haffner SM, Letho S, Ronnemaa T, Pyorala K, Laakso M. Mortality from coronary heart disease in subjects with type II diabetes and non diabetic subjects with and without prior myocardial infarction. N Engl J Med. 1998; 339(4):229-33.

[16] Garg A. What is the role of alternative biomarkers for coronary heart disease? Clin Endocrinol (Oxf). 2011;75(3):289-93.

[17] Tornvall P, Bavenholm P, Landou C, de Faire U, Hamsten A. Relation of plasma levels and composition of apolipoprotein B-containing lipoproteins to angiographically defined coronary artery disease in young patients with myocardial infarction. Circulation. 1993; 88(5 Pt 1):2180-9.

[18] Sniderman AD. Apolipoprotein B and apolipoprotein AI as predictors of coronary artery disease. Can J Cardiol. 1988; 4(Suppl A):24A-30A.

[19] Sedlis SP, Schechtman KB, Ludbrook PA, Sobel BE, Schonfeld G. Plasma apoproteins and the severity of coronary artery disease. Circulation. 1986; 73(5):978-86.

[20] Wägner AM, Jorba O, Rigla M, Alonso E, Ordóñez-Llanos J, Pérez A. LDLcholesterol/apolipoprotein B ratio is a good predictor of LDL phenotype B in type 2 diabetes. Acta Diabetol. 2002; 39(4):215-20. 
[21] Sniderman AD, Furberg CD, Keech A, Roeters van Lennep JE, Frohlich J, Jungner I, Walldius G. Apolipoproteins versus lipids as indices of coronary risk and as targets for statin treatment. Lancet. 2003; 361(9359):777-80.

[22] Planella T, Cortes M, Martinez-Bru C, Gonzalez-Sastre F, Ordonez- Llanos J. Calculation of LDL-Cholesterol by using apolipoprotein $B$ for classification of nonchylomicronemic dyslipemia. Clin Chem. 1997; 43(5):808-15.

[23] Walldius G, Jungner I, Aastveit AH, Holme I, Furberg CD, Sniderman AD. The apo $\mathrm{B} / \mathrm{apo}$ A-I ratio is better than cholesterol ratios to estimate the balance between plasma proatherogenic and antiatherogenic lipoproteins and to predict coronary risk. Clin Chem Lab Med. 2004;42(12): 1355-63.

[24] Walldius G, Jungner I . The apoB/apoA-I ratio: a strong, new risk factor for cardiovascular disease and a target for lipid-lowering therapy--a review of the evidence. J Intern Med. 2006; 259(5):493-519.

[25] Austin MA, Hokanson JE, Edwards KL. Hypertriglyceridemia as a cardiovascular risk factor. Am J Cardiol. 1998; 81(4A):7B-12B.

[26] Assmann G, Schulte H, Funke H, von Eckardstein A. The emergence of triglycerides as a significant independent risk factor in coronary artery disease. Eur Heart J. 1998; 19(Suppl M):M8-M14.

[27] Moliterno DJ, Lange RA, Meidell RS, Willard JE, Leffert CC, Gerard RD, Boerwinkle E, Hobbs HH, Hillis LD. Relation of plasma lipoprotein(a) to infarct artery patency in survivors of myocardial infarction. Circulation. 1993;88(3):935-40.

[28] Seman LJ, DeLuca C, Jenner JL, Cupples LA, McNamara JR, Wilson PWF, Castelli WP, Ordovas JM, Schaefer EJ. Lipoprotein(a)-cholesterol and coronary heart disease in the Framingham Heart Study. Clin Chem. 1999; 45(7):1039-46.

[29] Utermann G. The mysteries of lipoprotein (a). Science. 1989;246(4932):904-10.

[30] Rubiés-Prat J. Lipoproteína(a): del genotipo al riesgo cardiovascular, pasando por el fenotipo. Clin Invest Arterioscler. 2004; 16:151-3.

[31] Moeslinger T, Fiedl R, Volf I, Brunner M, Koller E, Spieckermann PG. Inhibition of nitric oxide synthesis by oxidized lipoprotein (a) in a murine cell line. FEBS Lett. 2000; 478(1-2):95-9.

[32] Von Eckardstein A, Schulte H, Cullen P, Assmann G. Lipoprotein(a) further increases the risk of coronary events in men with high global cardiovascular risk. J Am Coll Cardiol. 2001; 37(2):434-9.

[33] Nishino M, Malloy MJ, Naya-Vigne J, Russell J, Kane JP, Redberg RF. Lack of association of lipoprotein(a) levels with coronary calcium deposits in asymptomatic postmenopausal women. J Am Coll Cardiol. 2000; 35(2):314-20.

[34] Moliterno DJ, Jokinen EV, Miserez AR, Lange RA, Willard JE, Boerwinkle E, Hillis LD, Hobbs HH. No association between plasma lipoprotein(a) concentrations and the presence or absence of coronary atherosclerosis in African Americans. Arterioscler Thromb Vasc Biol. 1995; 15(7):850-5.

[35] Marcovina SM, Koschinsky ML, Albers JJ, Skarlatos S. Report of the National Heart, Lung, and Blood Institute Workshop on lipoprotein(a) and cardiovascular disease: recent advances and future directions. Clin Chem. 2003; 49(11):1785-96.

[36] Ridker PM, Hennekens CH, Buring JE, Rifai N. C-reactive protein and other markers of inflammation in the prediction of cardiovascular disease in women. $\mathrm{N}$ Engl J Med. 2000; 342(12):836-43. 
[37] Shishehbor $\mathrm{MH}$, Bhatt DL. Inflammation and atherosclerosis. Curr Atheroscler Rep. 2004; 6(2):131-9.

[38] Pearson TA, Mensah GA, Alexander RW, Anderson JL, Cannon RO 3rd, Criqui M, Fadl YY, Fortmann SP, Hong Y, Myers GL, Rifai N, Smith SC Jr, Taubert K, Tracy RP, Vinicor F; Centers for Disease Control and Prevention; American Heart Association. Markers of inflammation and cardiovascular disease: application to clinical and public health practice: A statement for healthcare professionals from the Centers for Disease Control and Prevention and the American Heart Association. Circulation. 2003; 107(3):499-511.

[39] Buckley DI, Fu R, Freeman M, Rogers K, Helfand M. C-reactive protein as a risk factor for coronary heart disease: a systematic review and meta-analyses for the U.S. Preventive Services Task Force. Ann Intern Med. 2009, 151(7):483-95.

[40] Healy H, Westhuyzen J. Biology and relevance of C-reactive protein in cardiovascular and renal disease. Ann Clin Lab Sci. 2000; 30(2):133-43.

[41] Refsum H, Ueland PM, Nygard O, Vollset SE. Homocysteine and cardiovascular disease. Annu Rev Med. 1998; 49:31-62.

[42] Kang SS, Wong PWK, Malinow MR. Hyperhomocyst(e)inemia as a risk factor for occlusive vascular disease. Annu Rev Nutr. 1992; 12:279-98.

[43] Malinow MR, Bostom AG, Krauss RM. Homocyst(e)ine, diet, and cardiovascular diseases: a statement for healthcare professionals from the Nutrition Committee, American Heart Association. Circulation. 1999; 99(1):178-82.

[44] Bostom AG, Rosenberg IH, Silbershatz H, Jacques PF, Selhub J, D'Agostino RB, Wilson PWF, Wolf PA. Nonfasting plasma total homocysteine levels and stroke incidence in elderly persons: the Framingham Study. Ann Intern Med. 1999; 131(5):352-5.

[45] Stehouwer CDA, Weijenberg MP, van den Berg M, Jakobs C, Feskens EJM, Kromhout D. Serum homocysteine and risk of coronary heart disease and cerebrovascular disease in elderly men: a 10-year follow-up. Arterioscler Thromb Vasc Biol. 1998; 18(12):1895-901.

[46] Woo KS, Chook P, Lolin YI, Sanderson JE, Metreweli C, Celermajer DS Folic acid improves arterial endothelial function in adults with hyperhomocysteinemia. J Am Coll Cardiol. 1999; 34(7):2002-6.

[47] Nygard O, Vollset SE, Refsum H, Stensvol I, Tverdal A, Nordrehaug E, Ueland M, Kvale G. Total plasma homocysteine and cardiovascular risk profile. The Hordaland Homocysteine Study. JAMA. 1995; 274(19):1526-33.

[48] Genest JJ, McNamara JR, Salem DN, Wilson PW, Schaefer EJ, Malinow MR Plasma homocyst(e)ine levels in men with premature coronary artery disease. J Am Coll Cardiol. 1990; 16(5):1114-9.

[49] Stampfer MJ, Malinow MR, Willett WC, Newcomer LM, Upson B, Ullmann D et al. A prospective study of plasma homocyst(e)ine and risk of myocardial infarction in US physicians. JAMA. 1992;268(7):877-81.

[50] Valkonen VP, Päivä H, Salonen JT, Lakka TA, Lehtimäki T, Laakso J, Laaksonen R. Risk of acute coronary events and serum concentration of asymmetrical dimethylarginine. Lancet. 2001; 358(9299): 2127-28

[51] Lu TM, Ding YA, Lin SJ et al: Plasma levels of asymmetrical dimethylarginine and adverse cardiovascular events after percutaneous coronary intervention. Eur Heart J. 2003; 24(21):1912-9. 
[52] Zoccali C, Bode-Böger S, Mallamaci F, Benedetto F, Tripepi G, Malatino L, Cataliotti A, Bellanuova I, Fermo I, Frölich J, Böger R. Plasma concentration of asymmetrical dimethylarginine and mortality in patients with end-stage renal disease: a prospective study. Lancet. 2001; 358(9299): 2113-17.

[53] Pitsavos C, Panagiotakos DB, Tambalis KD, Chrysohoou C, Sidossis LS, Skoumas J, Stefanadis C. Resistance exercise plus to aerobic activities is associated with better lipids' profile among healthy individuals: the ATTICA study. QJM. 2009, 102(9):609-16.

[54] Henderson GC, Krauss RM, Fattor JA, Faghihnia N, Luke-Zeitoun M, Brooks GA. Plasma triglyceride concentrations are rapidly reduced following individual bouts of endurance exercise in women. Eur J Appl Physiol. 2010, 109(4):721-30.

[55] Chomistek AK, Chiuve SE, Jensen MK, Cook NR, Rimm EB. Vigorous physical activity, mediating biomarkers, and risk of myocardial infarction. Med Sci Sports Exerc. 2011, Mar 25. [Epub ahead of print]

[56] Petruzzello SJ, Landers DM, Hatfield BD, Kubitz KA, Salazar W. A meta-analysis on the anxiety-reducing effects of acute and chronic exercise. Outcomes and mechanisms. Sports Med. 1991; 11(3):143-82.

[57] Taimela S, Viikari JS, Porkka KV, Dahlen GH. Lipoprotein (a) levels in children and young adults: the influence of physical activity. The Cardiovascular Risk in Young Finns Study. Acta Paediatr. 1994;83(12):1258-63.

[58] Mackinnon LT, Hubinger LM. Effects of exercise on lipoprotein(a). Sports Med. 1999; 28(1):11-24.

[59] Thomas NE, Baker JS, Davies B. Established and recently identified coronary heart disease risk factors in young people: the influence of physical activity and physical fitness. Sports Med. 2003; 33(9):633-50.

[60] Lippi G, Schena F, Salvagno GL, Montagnana M, Ballestrieri F, Guidi GC. Comparison of the lipid profile and lipoprotein(a) between sedentary and highly trained subjects. Clin Chem Lab Med. 2006;44(3):322-6.

[61] Kasapis C, Thompson PD. The effects of physical activity on serum C-reactive protein and inflammatory markers: a systematic review. J Am Coll Cardiol. 2005; 45(10):1563-9.

[62] Plaisance EP, Grandjean PW. Physical activity and high-sensitivity C-reactive protein. Sports Med. 2006; 36(5):443-58.

[63] Gonzales-Ordóñez AJ, Venta R, Terrados N, Arias A, Macias-Robles MD. Association between Sensitivity for Activated Protein C (APC) and Lipid or Lipoprotein Levels. Thrombosis and Haemostasis. 2002; 88: 1069-1070.

[64] Metsios GS, Stavropoulos-Kalinoglou A, Sandoo A, van Zanten JJ, Toms TE, John H, Kitas GD. Vascular function and inflammation in rheumatoid arthritis: the role of physical activity. Open Cardiovasc Med J. 2010; 4:89-96.

[65] Sadeghipour HR, Rahnama A, Salesi M, Rahnama N, Mojtahedi H. Relationship between C-reactive protein and physical fitness, physical activity, obesity and selected cardiovascular risk factors in schoolchildren. Int J Prev Med. 2010, 1(4):242-6.

[66] Dill DB, Costill DL. Calculation of percentage changes in volumen of blood, plasma, and red cells in dehydration. Journal of applied Physiology. 1974; 37(2):247-8.

[67] Bailey D, Davies B, Baker J. Training in hipoxia: modulation or metabolic and cardiovascular risk factors in men. Med Sci Sports Exerc. 2000; 32(6):1058-66. 
[68] König D, Bissé E, Deibert P, Müller H-M, Wieland H, Berg A. Influence of training volume and acute physical exercise on the homocysteine levels in endurancetrained men: interactions with plasma folate and vitamin B12. Ann Nutr Metab. 2003; 47(3-4):114-8.

[69] Wright M, Francis K, Cornwell P. Effect of acute exercise on plasma homocysteine. J Sports Med Phys Fitness. 1998; 38(3):262-5.

[70] De Crée C, Malinow MR, van Kranenburg GP, Geurten PG, Longford NT, Keizer HA. Influence of exercise and menstrual cycle phase on plasma homocyst(e)ine levels in young women-a prospective study. Scand J Med Sci Sports. 1999; 9(5):272-8.

[71] Venta R, Cruz E, Valcárcel G, Terrados N. Plasma vitamins, amino acids, and renal function in postexercise hyperhomocysteinemia. Medicine and Science in Sports and Exercise. 2009; 41(8):1645-1651.

[72] Arquer A, Elosua R, y J Marrugat. Actividad física y estrés oxidativo. Apunts Med Esport. 2010. doi: 10.1016/j. apunts.2009.12.002

[73] Schlager O, Giurgea A, Schuhfried O, Seidinger D, Hammer A, Gröger M, Fialka-Moser V, Gschwandtner M, Koppensteiner R, Steiner S. Exercise training increases endothelial progenitor cells and decreases asymmetric dimethylarginine in peripheral arterial disease: A randomized controlled trial. Atherosclerosis. 2011, 217(1):240-8.

[74] Seljeflot I, Nilsson BB, Westheim AS, Bratseth V, Arnesen H. The L-arginine-asymmetric dimethylarginine ratio is strongly related to the severity of chronic heart failure. No effects of exercise training. J Card Fail. 2011, 17(2):135-42. 


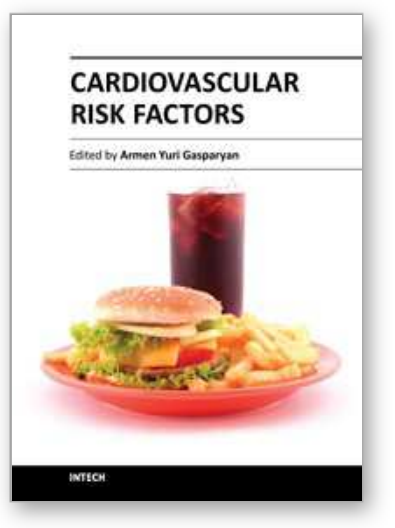

\author{
Cardiovascular Risk Factors \\ Edited by Prof. Armen Gasparyan
}

ISBN 978-953-51-0240-3

Hard cover, 498 pages

Publisher InTech

Published online 14, March, 2012

Published in print edition March, 2012

Cardiovascular risk factors contribute to the development of cardiovascular disease from early life. It is thus crucial to implement preventive strategies addressing the burden of cardiovascular disease as early as possible. A multidisciplinary approach to the risk estimation and prevention of vascular events should be adopted at each level of health care, starting from the setting of perinatology. Recent decades have been marked with major advances in this field, with the emergence of a variety of new inflammatory and immunemediated markers of heightened cardiovascular risk in particular. The current book reflects some of the emerging concepts in cardiovascular pathophysiology and the shifting paradigm of cardiovascular risk estimation. It comprehensively covers primary and secondary preventive measures targeted at different age and gender groups. Attention is paid to inflammatory and metabolic markers of vascular damage and to the assessment of vascular function by noninvasive standardized ultrasound techniques. This is a must-read book for all health professionals and researchers tackling the issue of cardiovascular burden at individual and community level. It can also serve as a didactic source for postgraduate medical students.

\title{
How to reference
}

In order to correctly reference this scholarly work, feel free to copy and paste the following:

Nicolás Terrados and Eduardo Iglesias-Gutiérrez (2012). New Cardiovascular Risk Factors and Physical Activity, Cardiovascular Risk Factors, Prof. Armen Gasparyan (Ed.), ISBN: 978-953-51-0240-3, InTech, Available from: http://www.intechopen.com/books/cardiovascular-risk-factors/new-cardiovascular-risk-factorsand-physical-activity

\section{INTECH}

open science | open minds

\section{InTech Europe}

University Campus STeP Ri

Slavka Krautzeka 83/A

51000 Rijeka, Croatia

Phone: +385 (51) 770447

Fax: +385 (51) 686166

www.intechopen.com

\section{InTech China}

Unit 405, Office Block, Hotel Equatorial Shanghai

No.65, Yan An Road (West), Shanghai, 200040, China 中国上海市延安西路65号上海国际贵都大饭店办公楼 405 单元

Phone: $+86-21-62489820$

Fax: $+86-21-62489821$ 
(C) 2012 The Author(s). Licensee IntechOpen. This is an open access article distributed under the terms of the Creative Commons Attribution 3.0 License, which permits unrestricted use, distribution, and reproduction in any medium, provided the original work is properly cited. 